\title{
Call for Special Issue Papers: Viral Oncolysis
}

\section{Deadline for Manuscript Submission: March 31, 2020}

\author{
Guest Editor: Janaina Fernandes, PhD; Universidade Federal do Rio de Janeiro
}

Infection of a tumor cell with a replication-competent virus, can result in the destruction of the tumor, but spares the neighboring normal cells; this is a new tool to treat cancer. These viruses are modified to specifically target cancer cells. In addition, this can lead to induction of host immune response to tumor cell antigens.

DNA and Cell Biology is organizing a special issue on Viral Oncolysis. We are looking for papers that will bring an innovative and integrated vision on the subject and provide state of the art information on the role of viral oncolysis in solid and hematological cancers to the scientific community.

We will consider articles highlighting the full breadth of scientific findings in the form of original research papers and reviews.

Areas of interest include, but are not limited to:

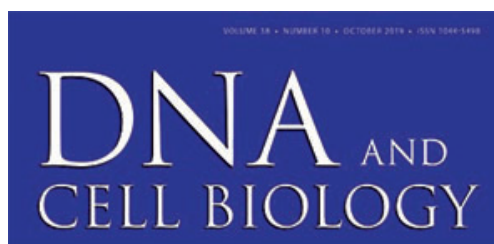

- Review of Viral Oncolysis

- Mechanisms of Resistance of tumors to Viral Oncolysis

- Treatment of solid and circulating tumors

- Markers of clinical efficacy of treatment

- New candidate viruses for viral oncolysis

- Checkpoint inhibitors and viral oncolysis

- Veterinary applications of viral oncolysis

- Adjuvant therapy and viral oncolysis

- In vivo studies

- Clinical trials

- Genetic variation among viruses used in oncolysis applications

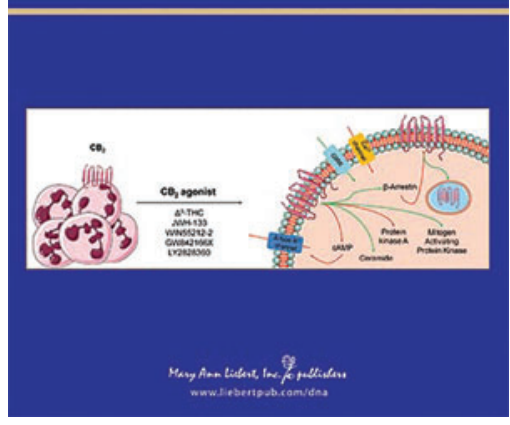

Contributions will receive prompt and thorough peer review. Please refer to our Instructions for Authors before submitting your manuscript for consideration. Authors are encouraged to vet ideas directly with Carol Shoshkes Reiss, our editor-in-chief, and Janaina Fernandes, the guest editor of the Special Focus issue via e-mail before submitting. Instructions for Authors can be found on our website at www.liebertpub.com/dna

DNA and Cell Biology delivers authoritative, peer-reviewed research on all aspects of molecular and cellular biology, with a unique focus on combining mechanistic and clinical studies to drive the field forward. The journal is under the editorial leadership of Editor-in-Chief Carol Shoshkes Reiss, PhD, Departments of Biology and Neural Science, New York University, and other leading investigators.

\section{Editorial Questions}

Janaina Fernandes, Guest Editor, E-mail: janainaf@biof.ufrj.br Carol Shoshkes Reiss, Editor-in-Chief, E-mail: carol.reiss@nyu.edu

Submit your paper for peer review online: https://mc.manuscriptcentral.com/dna 